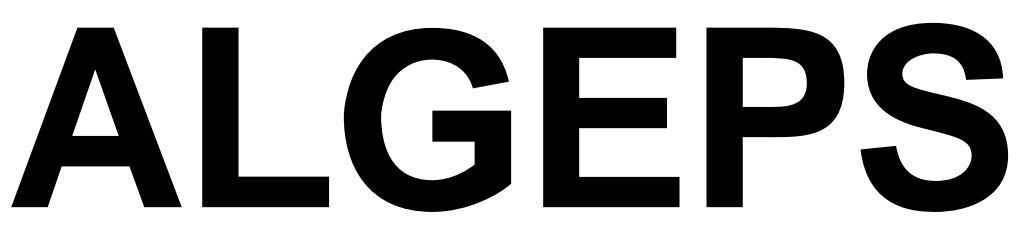

REVISTA DE GEOLOGIA, SÈRIE B no 648 - Setembre del 2013

RECORREGUT DE RECERCA GEOLÒGICA, GEOAMBIENTAL I MINERALÒGICA PER LES COMARQUES DEL BAIX LLOBREGAT I D'ANOIA: DES D'OLESA DE MONTSERRAT I ESPARREGUERA A PIEROLA, PIERA, VALLBONA I A CAPELLADES

Josep M. Mata-Perelló i Joaquim Sanz Balagué 


\title{
RECORREGUT DE RECERCA GEOLÒGICA, GEOAMBIENTAL I MINERALÒGICA PER LES COMARQUES DEL BAIX LLOBREGAT I D'ANOIA: DES D'OLESA DE MONTSERRAT I ESPARREGUERA A PIEROLA, PIERA, VALLBONA I A CAPELLADES / 28 DE GENER DEL 2012
}

\author{
Per Josep M. MATA-PERELLÓ i Joaquim SANZ BALAGUÉ
}

\section{ADVERTIMENTS PREVIS}

Com en altres recorreguts de RECERCA GEOLÒGICA I MINERALÒGICA ..., aquest constarà de diverses parades. Però, sols si es disposa del temps suficient, podrà efectuar-se passant per totes les parades $i$ filloles. En cas contrari, recomanem prescindir de les anomenades PARADES - CONDICIONALS.

Pel que fa als camins per on transitarà el recorregut de l'itinerari, cal dir que en general es trobaran en bones condicions. Tot i així, sempre que sigui possible, recomanem demanar la màxima informació, en relació al estat real dels camins. En cas de trobar-se en males condicions, recomanem fer el desplaçament a peu. En aquest itinerari seguirem alguns camins d'aquestes característiques, com el d'aproximació a Pierola.

En qualsevol cas, cal tenir sempre una cura molt especial de respecte a la natura, al llarg de tot el recorregut; de l'itinerari.

\section{BREU INTRODUCCIÓ}

El recorregut del present itinerari discorrerà, en la seva totalitat per una sola unitat geològica: pel Sistema Mediterrani (i més concretament, ho farà per dues de les quatre sotsunitats que el constitueixen: per la Depressió Prelitoral Catalana (per on s'iniciarà el recorregut, a Olesa de Montserrat) i per la Serralada Prelitoral Catalana (per on finalitzarà el recorregut, prop de Capellades).

Així, l'itinerari s'iniciarà a la localitat d'Olesa de Montserrat d'on s'anirà cap a Esparreguera, gairebé al contacte entre la Depressió Prelitoral Catalana i la Serralada Prelitoral Catalana. Pels voltants d'aquests pobles es faran les primeres aturades.

Després, en anar cap a Piera, es transitarà per la Depressió Prelitoral Catalana, on també es troba aquesta darrera població. Posteriorment, tot anant cap a Vallbona d'Anoia, s'entrarà a la Serralada Prelitoral Catalana. En aquest tram s'efectuaran diverses aturades, pels voltants de Pierola, Piera i Vallbona d’Anoia. 
Després, el recorregut es dirigirà cap a Capellades, per on s'efectuaran diverses aturades, totes dintre de la Serralada Prelitoral Catalana. Per les immediacions d'aquest darrer poble, es farà la darrera aturada, finalitzant el recorregut

Per d'altra banda, el recorregut de 1'itinerari, haurà anat oscil-lant entre la comarca del Baix Llobregat i la d'Anoia. En efecte, s'iniciarà a Olesa de Montserrat (Baix Llobregat), per a finalitzar a la població de Capellades (Anoia).

\section{OBJECTIUS FONAMENTALS}

Els objectius fonamentals que es pretenen aconseguir en el recorregut d'aquest itinerari, es poden concretar en els següents aspectes generals:

1.- Observació del Sistema Mediterrani, així com de les diferents sotsunitats que la constitueixen, i per les quals discorre el recorregut del present itinerari, entre les poblacions d'Olesa de Montserrat (comarca del Baix Llobregat) i la de Capellades (a la comarca d'Anoia).

2.- Observació i descripció dels materials paleozoics (exclusivament del Silurià i de 1’Ordovicià, així com de diversos afloraments granítics) i dels mesozoics (del Triàsic), amb un clar predomini dels primers. Aquests materials constitueixen el subsòl la Serralada Prelitoral Catalana, pels voltants de les poblacions per les quals discorrerà el recorregut de l'itinerari.

3.- Observació i descripció dels materials terciaris neògens (i més concretament del Miocè), els quals formen part de la Depressió Prelitoral Catalana, i que nosaltres trobarem pels voltants d'esparreguera, Pierola i Piera. Molt sovint, aquets materials es troben recoberts per terrenys detrítics quaternaris.

4.- Observació de les estructures locals d'aquests materials esmentats als paràgrafs anteriors, al llarg del recorregut de l'itinerari, així com de les relacions existents entre les sotsunitats que constitueixen el Sistema Mediterrani per aquests indrets (concretament per la Depressió Prelitoral Catalana i la Serralada Prelitoral Catalana).

5.- Observació i reconeixement de diverses mineralitzacions situades a diferents indrets del recorregut de l'itinerari, fonamentalment de les mineralitzacions filonianes de $\mathrm{Pb}-\mathrm{Zn}-\mathrm{Ba}-\mathrm{F}$, associades a fractures, encaixades entre els materials paleozoics de la Serralada Litoral Catalana. Nosaltres els veurem a la Mina de la Torre de la Fam (al terme de Piera).

6.- Observació, si s'escau, de diverses explotacions mineres, antigues i actuals, situades al recorregut de l'itinerari.

7.- Interpretació dels impactes mediambientals provocats per les explotacions mineres sobre el Medi Natural i sobre el Medi Ambient. I en tot cas de les restauracions dutes a terme per tal de corregir els impactes.

8.- Observació de l'important Patrimoni Geològic que anirem trobant al llarg d'aquest itinerari, com: les Flandes (Piera), el Balcó de Capellades (en aquesta població).

9.- Observació del Patrimoni Miner relacionat amb les explotacions mineres, en concret del relacionat amb la Mina de la Torre de la Fam (a Piera). 


\section{ANTECEDENTS BIBLIOGRÀFICS}

Pel que fa al recorregut del present itinerari, existeixen alguns antecedents parcials, de tipus bibliogràfic referent a diferents parts del recorregut del mateix; es tracta de MATAPERELLÓ (1996a, 1996b, 1997, 1998, 1999a,1999b, 2001a, 2002b, 2005, 2006 i 2007). I també a MATA LLEONART et altri (2001); així com a MATA-PERELLÓ i FALGUERA TORRES (2004). Trets d'aquests antecedents, no en tenim coneixement de cap altres.

Tot i així, farem esment d'un important treball de SOLE SABARÍS (1964), on es descriu un recorregut molt proper al que ara presentem, dintre d'un conjunt de recorreguts pels voltants de Barcelona.

Pel que fa a la descripció de les mineralitzacions de les comarques per les quals discorre l'itinerari, cal parlar d'uns altres treballs nostres, de MATA-PERELLÓ (1988 i 1991), el primer relatiu al conjunt de les mineralitzacions catalanes en general, distribuïdes per comarques, $\mathrm{i}$ esmentant-se les corresponents al Baix Llobregat i al Vallès Occidental. També pot fer-se esment del treball comarcal de MATA-PERELLÓ (1988), en un treball relatiu a la comarca del Vallès Occidental i a la del Baix Llobregat.

I, finalment, pel que fa a l'estructura geològica de la zona per la qual discorre l'itinerari, farem esment dels treballs de: GUIMERÀ et altri (1982) i de RIBA et altri (1976). Tanmateix, farem esment de les fulles de IGME (1976a i 1976b) relativa a la zona per on discorre el recorregut del present itinerari.

Tots aquests treballs referenciats, i d'altres, figuren esmentats per ordre alfabètic a l'apartat dedicat a la BIBLIOGRAFIA.

\section{RECORREGUT DE L'ITINERARI}

L'iniciï del recorregut de l'itinerari, s'iniciarà a la població d'Olesa de Montserrat, molt prop del contacte entre la Depressió Prelitoral Catalana i la Serralada Prelitoral Catalana. El poble es troba sobre la primera unitat geològica esmentada. Tot seguit, el recorregut es dirigirà cap a la propera població d'Esparreguera (situada al Baix Llobregat, com l'anterior). Prop del poble es realitzaran dues aturades.

Després, el recorregut es dirigirà cap a les immediacions de Pierola, passant del Baix Llobregat a la comarca d'Anoia. Prop de la darrera població, efectuarem una nova parada, dintre de la Depressió Prelitoral Catalana.

Després el recorregut s'encaminarà cap a Hostalets de Pierola i cap a Piera. Prop de la darrera, realitzaran diverses primeres aturades del recorregut, unes dintre de la Depressió Prelitoral Catalana (a l'argilera del Badorc) i altres a Serralada Prelitoral Catalana (com a les Mines de la Torre de la Fam).

Després. el recorregut es dirigirà cap a les poblacions de Vallbona d'Anoia i Capellades. En aquest tram es realitzaran diverses aturades abans de finalitzar el recorregut a la darrera població esmentada. 


\section{DESCRIPCIÓ DE L'ITINERARI}

Com ja es habitual, s'estructurarà en una sèrie d'estacions (parades o aturades), en les qual es faran descripcions geològiques o mineralògiques, si s'escau. En cada cas s'indicarà el número del mapa topogràfic a escala 1:50.000 on es troba l'indret. En aquest cas, el recorregut de l'itinerari passarà exclusivament per dos dels fulls. Concretament ho farà per part del $\mathbf{3 9 1}$ (o d'Igualada), 392 (o de Sabadell) i 420 (dit de l'Hospitalet de Llobregat), de 1'"Instituto Geográfico y Catastral", realitzat a l'escala de 1:50.000.

Així doncs, la relació i descripció de les aturades que composen aquest itinerari, és la següent:

PARADA 1. LES BALMES, (Colònia Sedó, terme municipal d'Esparreguera, comarca del Baix Llobregat - Nord). (Full 392).

Tot i que el recorregut de l'itinerari l'haurem iniciat a la població d'Olesa de Montserrat, prop de 1'Estació del Ferrocarrils Catalans, ens caldrà sortir del poble per la carretera C-1414, la qual condueix cap a Esparreguera. Tot i així, després de creuar el riu Llobregat, ens caldrà agafar la carretera que condueix cap a la Colònia Sedó. A uns 100 metres del seu inici, farem la primera aturada. Així, des del principi del recorregut haurem fet un trajecte d’uns 1'5Km i escaig.

Tot aquest breu recorregut, s'efectua íntegrament per entre els materials cenozoics i quaternaris que constitueixen la Depressió Prelitoral Catalana, on ara ens trobem. Tot i així, la major part del recorregut s'ha efectuat entre afloraments detrítics del segon. Malgrat això, a l'inici de la carretera que procedeix de la Colònia Sedó (a uns $100 \mathrm{~m}$, de la seva fi), es pot observar al mateix costat d'ella un interessant aflorament de travertins quaternaris, situats sobre els sediments detrítics miocènics. Dintre dels travertins s'ha desenvolupat un carst, que ha donat lloc a la formació d'una sèrie de coves, generalment petites, que constitueixen les anomenades "Balmes del Fabricó". FOTOGRAFIA 1.

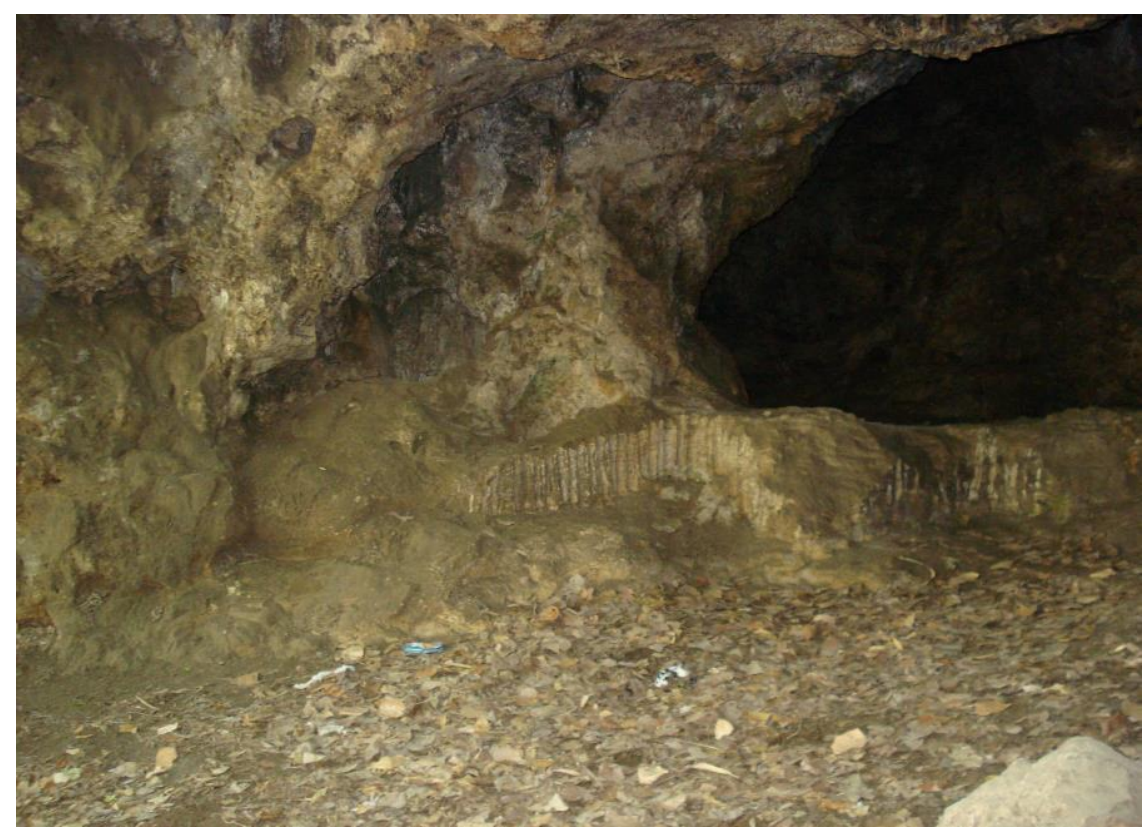

FOTOGRAFIA 1 
Les Balmes, amb una petita extracció dels travertins

Prop d'aquest, hi ha altres afloraments de travertins quaternaris, situats per sobre dels materials miocènics, i que es troben generalment a més alçada que el que es localitza a la present parada. Sobre dels altres afloraments, també s'han desenvolupat estructures càrstiques similars a la que acabem de veure.

Per d'altra banda, des d'aquest indret, i mirant cap al NE, es pot veure en primer terme la terrassa baixa del riu Llobregat, sobre el que s'ha situat el Polígon Industrial d'Olesa; així com la terrassa mitja, sobre la qual ha anat creixent la població.

Més enllà, es poden veure els relleus paleozoics (en primer terme, arrodonits), i els mesozoics del Triàsic (en segon terme, i més escarpats). Fins i tot, dintre d'aquest darrer, es poden distingir clarament els trams que el constitueixen. Al respecte, cal dir que tots aquests materials formen part de la Serralada Prelitoral Catalana, i més concretament dels relleus del Puig Cendrós i del Puig Ventós, entre altres indrets de la mateixa.

PARADA 2. CAMÍ DE CAN FONT, (terme municipal d'Esparreguera, comarca del Baix Llobregat - Nord). (Full 392).

Després de fer l'aturada anterior, cal retornar cap a la carretera C - 1414, amb la intenció de continuar ascendint cap a Esparreguera. En arribar-hi cal al camí vell de Collbató, tot travessant la població per les immediacions de 1'Església. A la sortida del poble arribarem a les proximitats del Pla de Can Font., abans d'arribar-hi, ens caldrà fer una nova aturada, a uns 4 $\mathrm{Km}$.

En aquest recorregut, inicialment hem anat trobant afloraments dels materials esmentats a les aturades anteriors. Després, haurem vist com aquests materials han quedat recoberts per terrenys detrítics quaternaris. Aquests materials són els que ara apareixen a la mateixa vora del camí, on es possible veure interessants exemples de podosòls. FOTOGRAFIA 2.

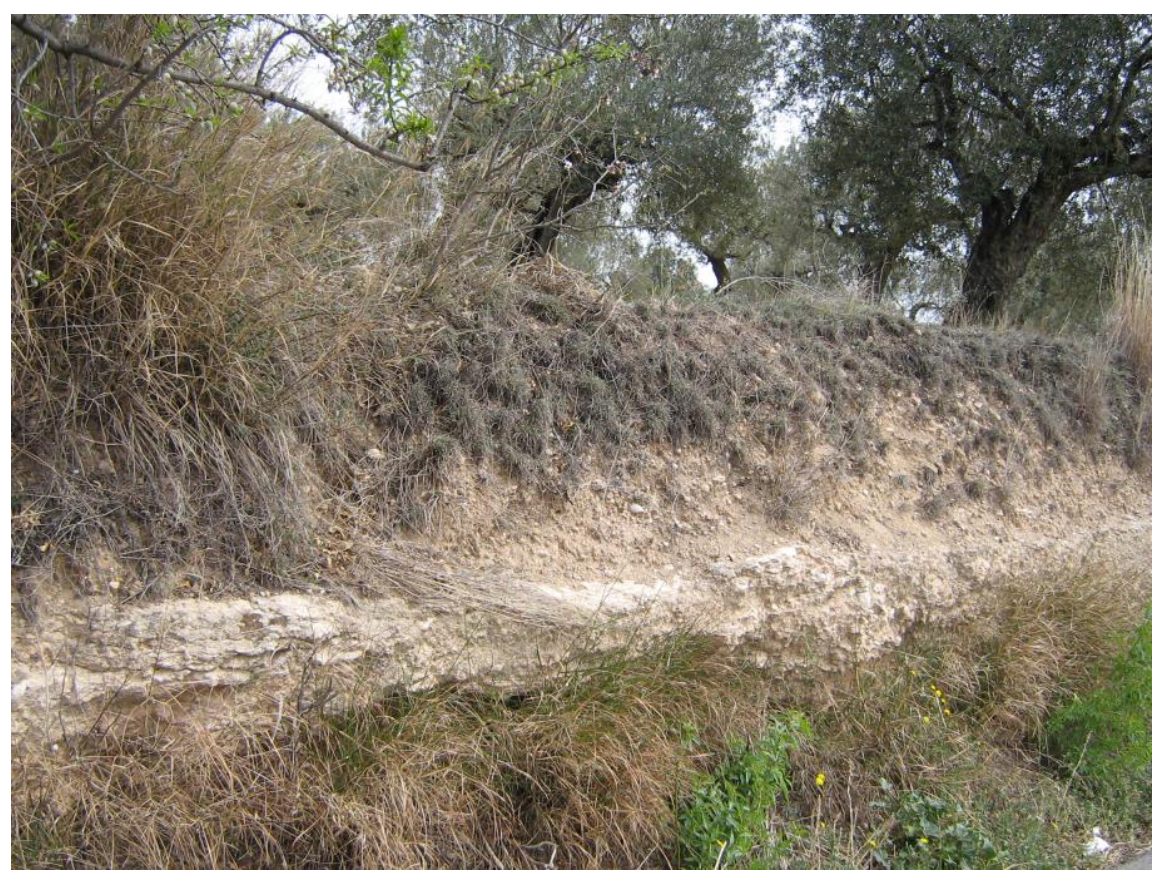


Podosòls a la bora del camí

PARADA 3. PLA DE CAN FONT, (terme municipal d'Esparreguera, comarca del Baix Llobregat - Nord). (Full 392).

Després de fer l'aturada anterior, cal continuar cap a les proximitats del Pla de Can Font. Aquí ens caldrà fer una nova aturada, aproximadament a uns 0’5 Km de l'anterior.

En aquest breu recorregut, haurem anat trobant afloraments dels materials quaternaris esmentats a la parada anterior, concretament dels anomenats podosòls, que pràcticament haurem trobat fins al lloc de la present aturada.

Des d'aquest indret, es pot veure una ampla panoràmica del Torrent de Roques Blaves, per sobre del qual estem situats. Així es veuen interessants exemples de xaragalls desenvolupats sobre aquests materials. Al respecte d'aquests, cal dir que es tracta de llicorelles trinxades per la falla Nord del Vallès-Penedès, de color blavós. FOTOGRAFIA 3.

En relació a la falla, hem de dir que no la veiem, encara que estem situats davant de la seva bretxa de falla: les llicorelles trinxades que hem acabat d'esmentar. Aquesta falla posa en contacte les llicorelles paleozoiques situades al Nord d'on ara som, i els materials detrítics del Miocè, situats al Sud. Les primeres es troben a la Serralada Prelitoral Catalana; mentre que les segones es troben a la Depressió Prelitoral Catalana.

Per d'altra banda, des d'aquest indret es pot veure una interessant finestra tectònica, ja que per sota de les pissarres, apareixen (al fons del barranc) uns materials rogencs amb gresos i calcolutites, que pertanyen al Triàsic Inferior, al Buntsadsteim.

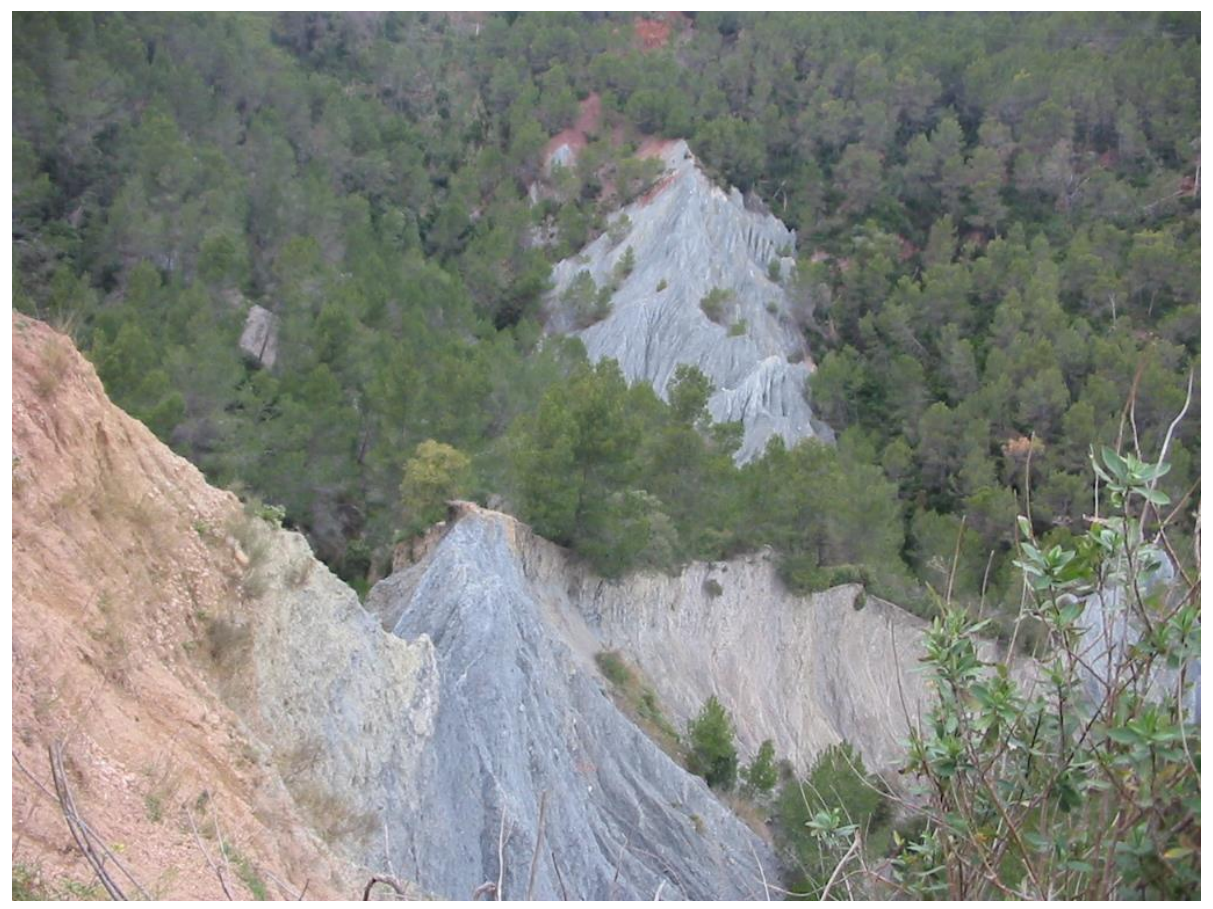

FOTOGRAFIA 3

Xaragall de Roques Blaves, Esparreguera 
Tanmateix, mirant a l'altra banda del torrent, es pot veure una falla que posa en contacte els materials rogencs del Buntsandsteim amb les llicorelles de 1'Ordovicià. La falla es vertical i es fa palesa a diferents zones, enfront nostre.

Des d'aquest lloc es pot gaudir de l'observació (a l'altra banda del torrent) dels diferents materials triàsics, donant lloc a un interessant tall. Així, sobre els gresos i calcolutites rogenques del Triàsic Inferior (del Buntsandsteim), es poden veure els diferents trams del Triàsic Mitjà: les calcàries i dolomies del Muschelkalk Inferior, els gresos i calcolutites roges del Muschelkalk Mig i les calcàries i dolomies del Muschelkalk Superior, al Coll de Can Colomer.

Tanmateix, per darrera de tots els materials anteriors, es poden veure els nivells de conglomerats i bretxes calcaries de 1'Eocè, tot formant part de Montserrat. Precisament, aquesta muntanya es fa ja clarament palesa per darrera dels materials mesozoics, tot i que entre uns i altres hi ha la Riera de la Salut, que baixa al Llobregat pels voltants de Ca n`Estruc.

Finalment, cal dir que aquest paratge on ara som, és un indret molt interessant del nostre patrimoni geològic, que cal conservar adequadament.

PARADA 4. TRENCALL DE PIEROLA, (Pierola, terme municipal dels HOSTALETS DE PIEROLA, comarca d'Anoia). (Full 391).

Després de fer la parada anterior, cal retornar cap a Esparreguera. Aquí, cal seguir per la carretera que es dirigeix cap al poble d'Hostalets de Pierola, la B - 231. En arribar al trencall de Pierola, cal fer una nova aturada, a uns $15 \mathrm{Km}$ de l'anterior.

En aquest recorregut hem travessat, part de la Depressió Prelitoral Catalana, on érem ja a la parada anterior. Així, hem circulat per entre afloraments quaternaris, els quals cobreixen als materials miocènics que reblen la depressió. Aquests materials quaternaris són molt detrítics i a pareixen formant ventalls.

Ara estem situats en aquesta unitat geològica, concretament al sector conegut geogràficament com a Depressió del Penedès. Aquí es fan clarament palesos aquests materials quaternaris, eminentment detrítics, que hem esmentats. En especial es poden veure als marges de la riera, per on hi ha el vell poblet de Pierola, en part cobert de vegetació, tret d'algunes cases escampades.

Per d'altra banda, es pot veure cap al NE el relleu de Montserrat, el qual sobresurt de tots els que l'envolten. Aquests relleus llunyans pertanyen a la Depressió Geològica de l'Ebre.

\section{PARADA 4. LES FLANDES, (terme municipal de Piera, comarca d'Anoia). (Full 391).}

Després de fer l'aturada anterior, cal seguir cap a les immediacions del poblet d'Hostalets de Pierola i cap a Piera. En arribar a aquest darrer poble, cal seguir per la carretera que es dirigeix cap al Badorc (i cap a Sant Sadurní d'Anoia), la carretera BV - 2242. A uns 2 $\mathrm{Km}$ del trencall, cal fer una nova aturada, a uns $7 \mathrm{Km}$ de l'anterior.

En aquest recorregut, hem anat circulant per la Depressió Geològica de l’Ebre, entre els 
materials terciaris del Miocè, els quals es troben molt sovint recoberts per terrenys detrítics quaternaris, com hem vist abans.

Així en aquest lloc, ens trobem davant d'un aflorament dels materials miocènics constituïts per alternances de eludides de tonalitats ocres, per gresos, i per filades de còdols i palets procedents de l'erosió de les pissarres de la Serralada Prelitoral Catalana, que es troben més amunt i que veurem després.

En aquest indret es troben unes interessants formacions de xaragalls (o "bad-lands"), desenvolupats sobre els nivells de eludides miocèniques. Aquests abarrancaments han conduït a la formació d'un conjunt molt bonic, el qual s'anomena amb el nom de les Flandes. Sense cap mena de dubte, tant per la seva espectacularitat i bellesa, com seu indubtable valor didàctic, es un indret molt important de la nostra geologia. És més creiem que es tracta d'un àrea a protegir (MATA-PERELLÓ i FONT, 1995). FOTOGRAFIA 4.

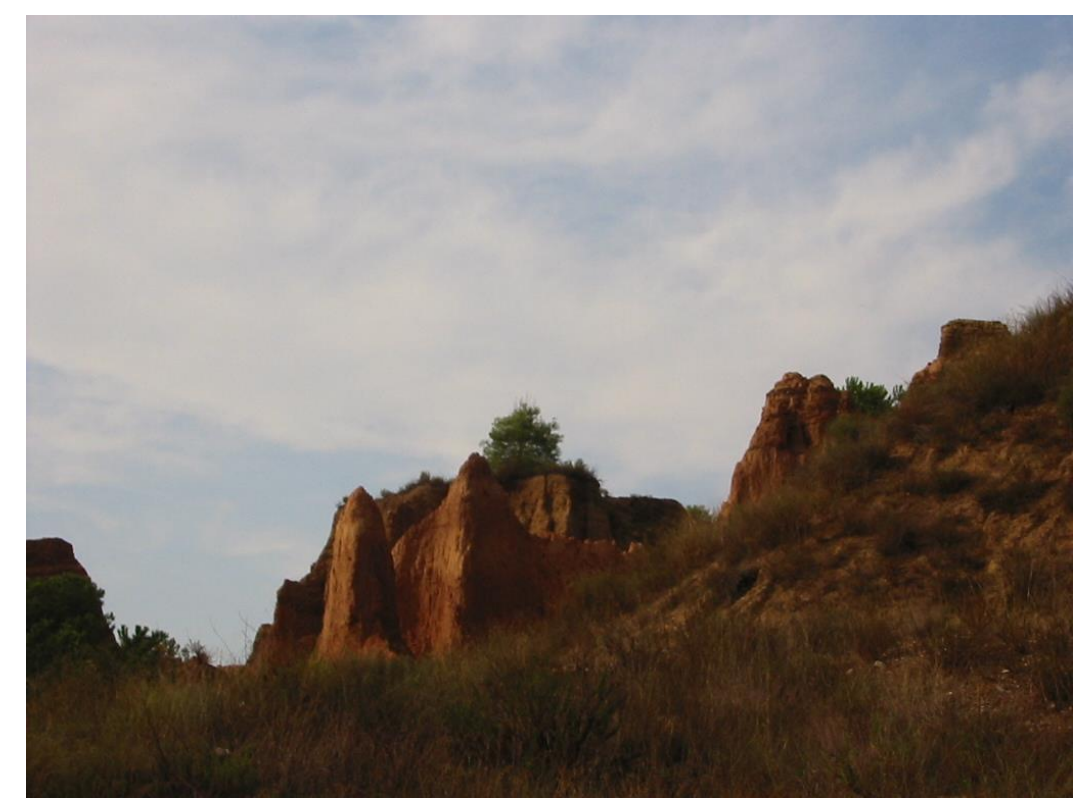

FTOGRAFIA 4

Aspecte dels materials miocènics axaragallats a les Flandes (Piera, el Badorc)

Des del nostre punt de mira es un important $P I G$ (Punt d'Interès Geològic), integrant del que podria ser el Parc Geològic de la Catalunya Central (MATA-PERELLÓ, 2004). Es, sense cap mena de dubte un punt interessant de la geologia de la comarca d'Anoia.

PARADA 5 - CONDICIONAL. MINES DEL TORRENT DE LA TORRE DE LA FAM, (Ca N'Aguilera, terme municipal de Piera, comarca d'Anoia). (Full 391).

Des de la parada anterior, cal anar de nou cap a Piera. Des d'aqui ens cal seguir cap a Vallbona d'Igualada, fins arribar a les immediacions de la Urbanització de la Venta, prop del Km 6’2 de la carretera, es trobarà un trencall per l'esquerra, que haurem d'agafar.

Tot seguit, cal continuar pel camí, fins arribar a un torrent. Després cal seguir aquest camí tota l'estona, sempre pel fons del torrent. En arribar a l'indret en que el camí-torrent 
passa per sota d'una línia d'alta tensió, cal cercar un camí que va de torre en torre, fins arribar a la segona. Per sota d'ella hi ha les mines que busquem, $i$ on farem la present aturada. Així, des de l'inici del recorregut, s'hauran recorregut uns $6 \mathrm{Km}$, aproximadament.

Les mines es troben localitzades sobre unes mineralitzacions filonianes, les quals encaixen entre les llicorelles paleozoiques (que pertanyen possiblement a l'Ordovicià). Els filons, gairebé verticals, tenen una amplada variable de $20-30 \mathrm{~cm}$, essent de direcció aproximada d'E-O. FOTOGRAFIA 5.

Entre els minerals presents es troben: PIRITA (és el mineral més abundant), FLUORITA (era el mineral explotat) i QUARS. Al respecte del segon mineral, cal dir que és molt fluorescent, doncs dintre té un color més aviat verdós, i fora en té un altre de brumarronós. També es troben altres minerals com: BARITINA (molt abundant) i CALCITA; així com indicis d'ESFALERITA $i$ de GALENA.

Tanmateix es troben diversos minerals d'alteració, formats a partir de la pirita, especialment. Així hi ha abundants mostres de GOETHITA (sempre terrosa i limonititzada, $i$ ben palesa ja a la mateixa entrada a la mina) i MELANTERITA. També hi ha indicis de CEUSSITA $i$ d'ANGLESITA, formades a partir de l'alteració de la galena.

Finalment, cal dir que per a visitar les mines, és necessari portar llum artificial, $i$ un casc protector. També es aconsellable portar botes d'aigua. Però, en qualsevol cas, cal tenir força cura, doncs a uns $12 \mathrm{~m}$ de l'entrada hi ha una galeria descendent, amb forta inclinació inversa al sentit de l'entrada, i freqüentment coberta d'aigua. ULL!!.

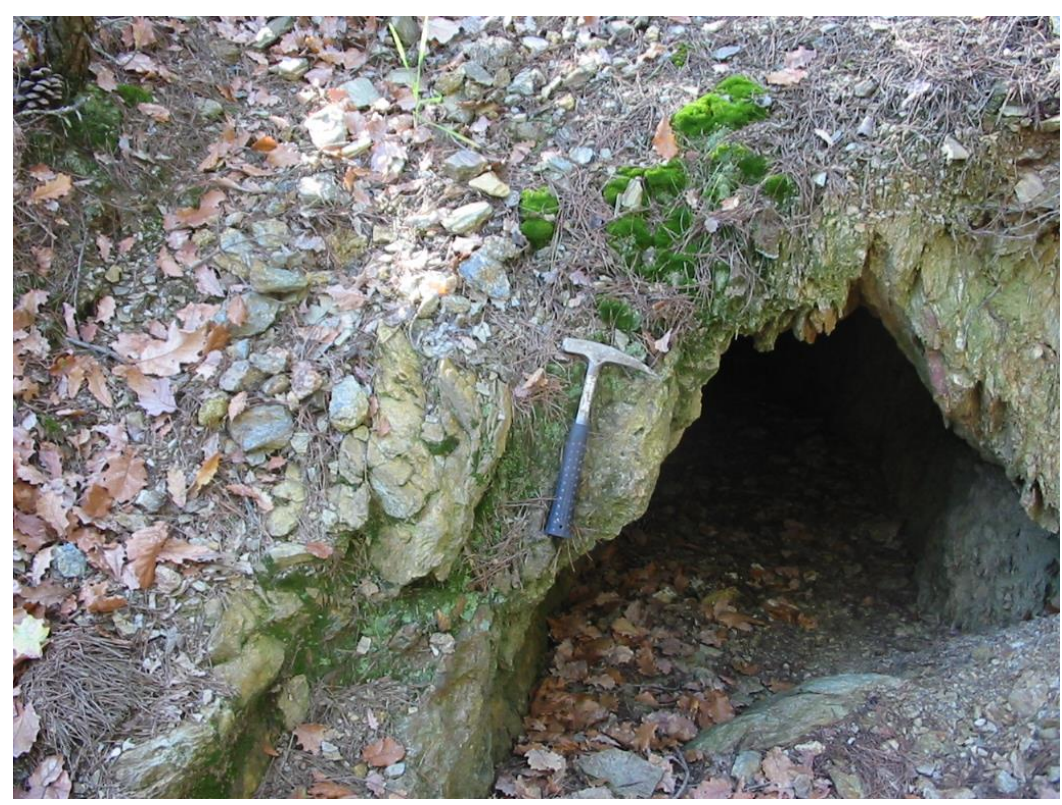

FOTOGRAFIA 5

Boca superior de les Mines de la Torre de la Fam, de Piera

\section{PARADA 6. PEDRERES DE SAULÓ, (terme municipal de Vallbona d'Anoia, o d'Igualada, comarca d'Anoia). (Full 391).}

Des de la parada anterior car retornar cap a carretera B-224, per tal d'agafar a la, per tal 
de continuar cap a llevant, anant cap a Vallbona d'Anoia (o d'Igualada), que s'haurà de sobrepassar. Poc després, ens caldrà parar a les explotacions de sauló, situades a uns $500 \mathrm{~m}$ del poble, a la dreta de la carretera. Així, des de la parada anterior, s'haurà fet un recorregut proper als 5’5 $\mathrm{Km}$.

En qualsevol cas, tot el recorregut des de la parada anterior s'efectua entre els afloraments paleozoics de llicorelles de la Serralada Prelitoral Catalana. Tot i així, ben a prop de Vallbona, s'han començat a trobar els afloraments de granodiorites i de granits, sobre els quals ara ens trobem.

En aquest indret, on es fa la present parada, es troben uns dels afloraments esmentats de granodiorites (més grisenques), i de granits (més rosats). Entre ells es troben freqüents dics de pòrfirs. Cal dir que tant uns com altres es troben meteoritzats i transformats en sauló. Aquests materials, d'aspecte sorrenc, són explotats com a material de construcció. FOTOGRAFIA 6.

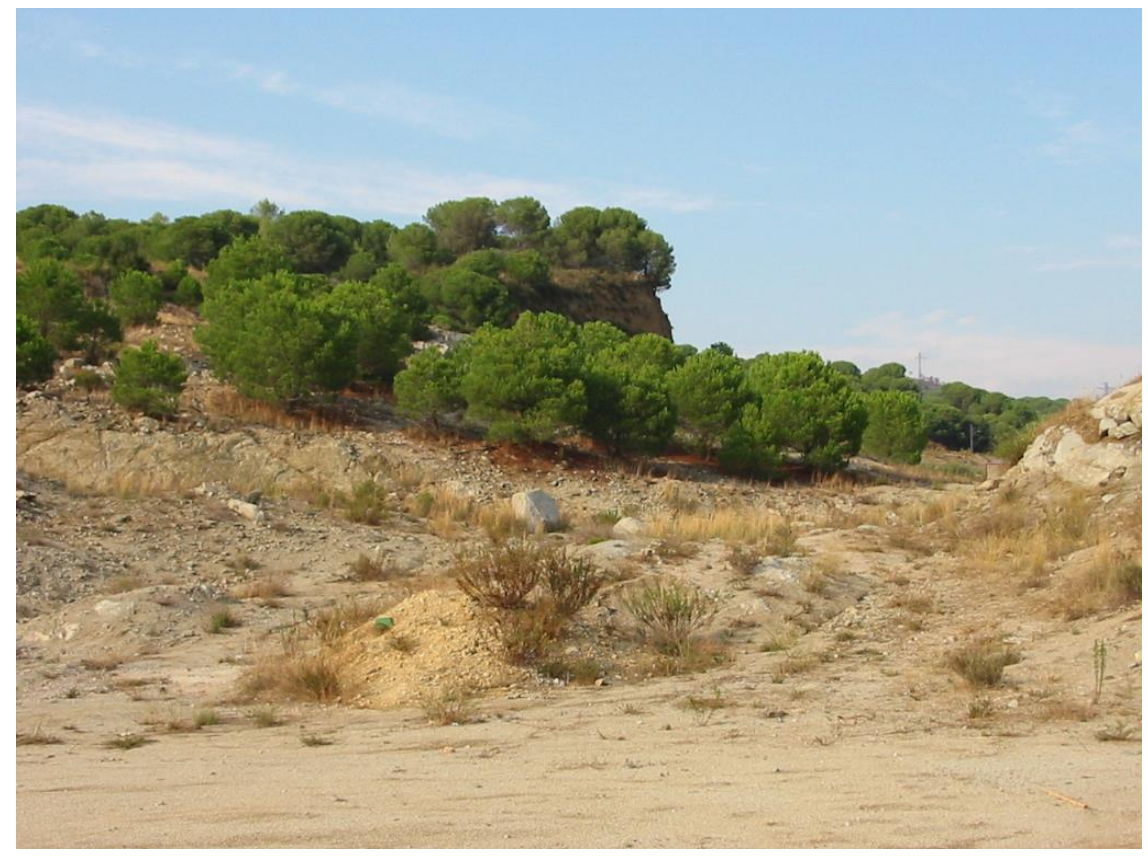

FOTOGRAFIA 6

Les sauloneres de Vallbona d'Anoia

Per d'altra banda, cal dir que els materials granítics es troben en contacte amb unes llicorelles paleozoiques, a les quals els hi confereixen un cert grau de metamorfisme de contacte.

També cal dir que s'observa la presència de petits filonets de QUARS, alguns dels quals contenen mineralitzacions de coure, amb presència de CALCOPIRITA; la qual, per alteració, ha donat lloc a la formació d'ATZURITA, i sobretot a l'abundant presència de MALAQUITA. Igualment, cal esmentar l'existència d'abundants dendrites de PIROLUSITA.

Finalment, cal dir que tot el conjunt dels afloraments anteriors, queda cobert cap al Nord, per una terrassa quaternària, corresponent al proper riu Anoia.

PARADA 7. CONGOST DEL RIU ANOIA, (terme municipal de Capellades, 
comarca d'Anoia). (Full 391).

Des de la parada anterior, cal continuar per la carretera C-242, fins arribar a Capellades. Un cop al poble, ens cal anar cal a 1' anomenat Balcó de Capellades, per on farem aquesta nova aturada. Així, des de la parada anterior, s'haurà efectuat un recorregut proper als 3'5 Km, per tal d'arribar fins on ara som.

En aquest indret, es pot gaudir d'un bon lloc d'observació del Congost del riu Anoia, excavat entre els nivells de llicorelles paleozoiques (que pertanyen, molt probablement a l'Ordovicià). Aquestes llicorelles són d'unes tonalitats gris-fosques, i es troben molt menys alterades que les que hem vist a la novena aturada. FOTOGRAFIA

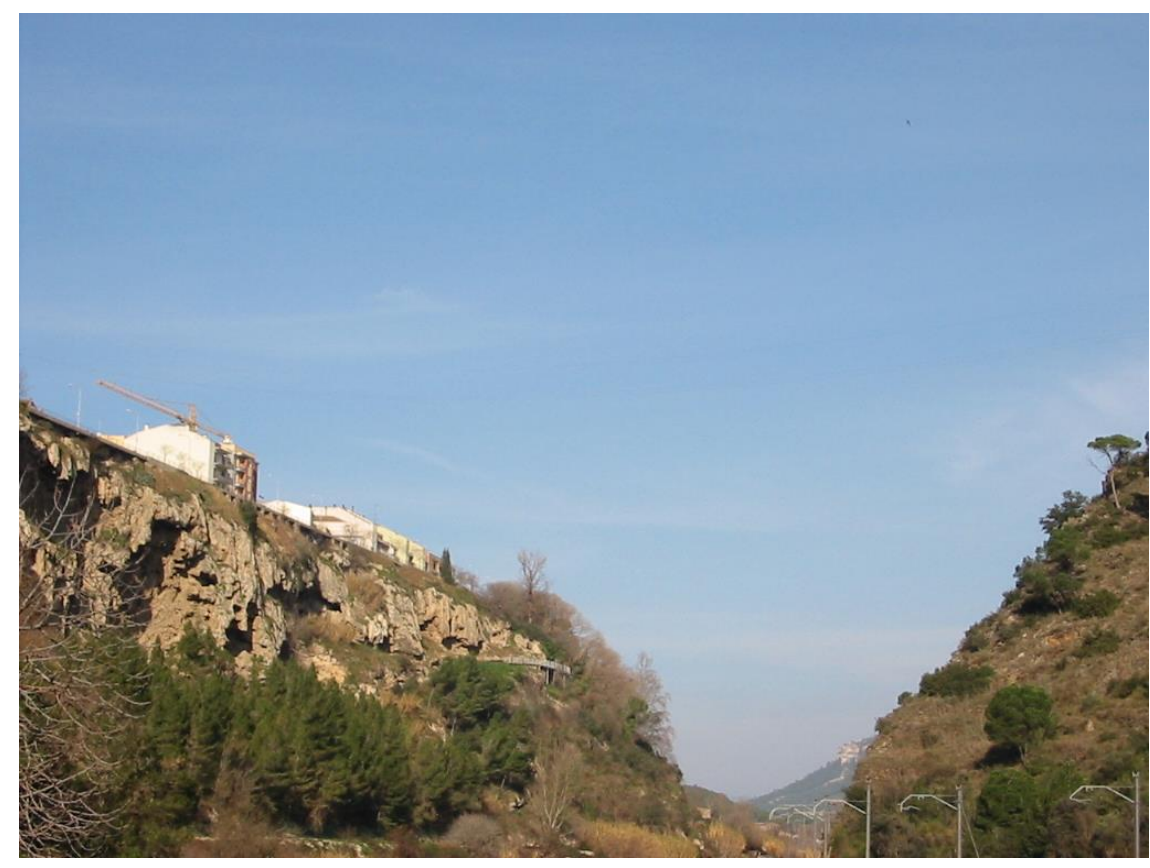

FOTOGRAFIA 7

Congost de 1'Anoia a Capellades. El poble sobre el "Balcó de Capellades"

En aquest recorregut, hem anat trobant els materials paleozoics esmentats a la parada anterior. Tanmateix hem trobat uns nivells carbonatats del Triàsic (del Muschelkalk Inferior). Uns i altres pertanyen a la Serralada Prelitoral Catalana, on ara som. Per d'altra banda, sobre els materials anteriors, es troben uns afloraments de nivells carbonatats travertínics que pertanyen al Quaternari. Aquests nivells donen idea d'una possible i alhora important formació lacustre que devia entendre's per aquests indrets. FOTOGRAFIA 8.

Aquesta formació lacustre, es trobaria originada com a conseqüència d'abundants surgències d'aigües carregades de bicarbonat càlcic, procedents possiblement dels trams carbonatats del Muschelkalk; concretament de 1'Inferior i del Superior. Aquests trams carbonatats es troben més amunt, i també es fan força palesos a Cabrera d'Igualada.

Per d'altra banda, cal fer esment de l'existència de cavitats kàrstiques entre els travertins, com les que han donat lloc a la formació de l'Abric Romaní, amb abundants restes arqueològics. 
Des d'aquest indret on ara som, es poden veure tots aquests materials travertínics. Per d'altra banda es fa molt patent el congost del riu Anoia. Tot aquest conjunt, constitueix un important PIG (Punt d'Interès Geològic) de la Catalunya Central.

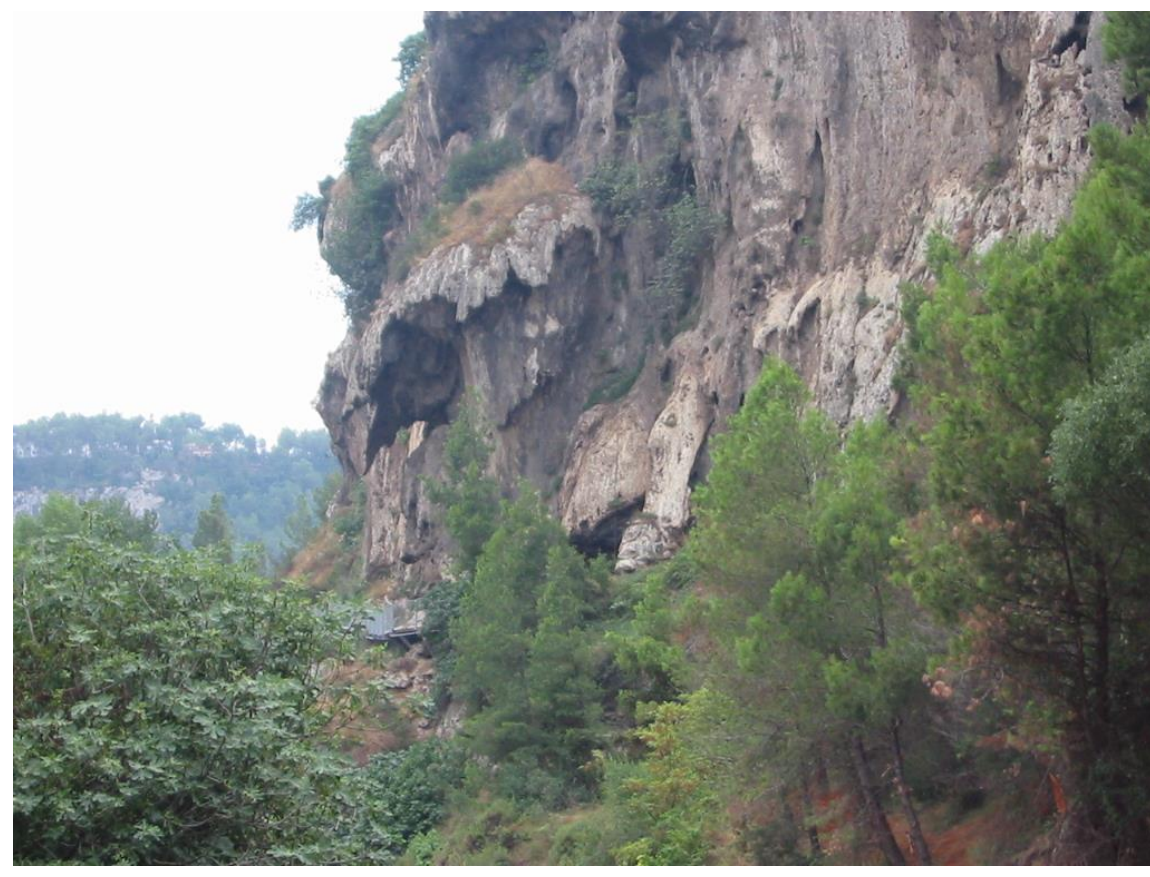

FOTOGRAFIA 8

Els travertins de l'Abric Romaní, sota del Balcó de Capellades

\section{AQUÍ FINALITZA EL RECORREGUT DE L’' ITINERARI}

\section{REFERÈNCIES BIBLIOGRÀFIQUES}

CABRERA, L. (1983).- Estratigrafia de las formaciones lacustres del tránsito Oligoceno Mioceno, del SE de la Cuenca del Ebro. Tesis Doctoral, Dep. Estratigrafia i Geologia Històrica. Univ. de Barcelona, Vol. 1,443 pag. Barcelona

GUIMERÀ, J. et altri (1992).- Geologia (II), Història Natural dels Països Catalans, Vol.2, 547 pag. Enciclopèdia Catalana, S.A. Barcelona

IGME (1975).- Explicación del Mapa Geològico de España, a escala 1:50.000. Segunda serie. Hojas número: 391 (Igualada), IGME. Madrid

MASACHS, V. et altri (1981).- Itineraris Geològics per les comarques del Bages, Berguedà, Solsonès i Anoia. Pub. Centre d'Estudis Geològics - Caixa d'Estalvis de Manresa. 205 pag. Manresa 
MATA-PERELLÓ, J.M. (1990).- Inventari Mineralògic de la comarca d'Anoia. Revista Xaragall, $\mathrm{n}^{\circ}$ 24, 40 pag. Manresa

MATA - PERELló, J.M. (1991).- Els Minerals de Catalunya. Arxius de la Secció de Ciències, t. XCIII, 442 pag. Institut d'Estudis Catalans. Barcelona

MATA-PERELLÓ, J.M. (1996a).- Itinerari geològico - mineralògic per la comarca d'Anoia: des d’Òdena a la Tossa de Montbui, a Carme i a la Pobla de Claramunt. Inèdit. 12 pàg. Manresa

MATA - PERELLÓ, J. M. (1996b).- Itinerari geològico-mineralògic per la comarca d'Anoia (amb una petita incursió per l’Alt Penedès): des de Piera a Capellades i a Castellolí. Apunts EUPM, 15 pàgines. Manresa

MATA-PERELLÓ, J.M. (1996c).- Recerca Geològica i Mineralògica per la comarca d'Anoia: de Piera a Vallbona d'Anoia i a Capellades, 11pàg. Apunts EUPM, Manresa

MATA-PERELLÓ, J.M. (1997).- Recorre. de recerca geològic. i mineralògic per la comarca d’Anoia: des del Bruc a Capellades i a Cabrera d'Anoia, Inèdit, 12pag. Manresa

MATA-PERELLÓ, J.M. (1997).- Recerca Geològica i Mineralògica per les comarques del Baix Llobregat i del Vallès Occidental: des de Castellbisbal a Martorell i a Esparreguera. Inèdit, 12 pàgines. Manresa

MATA-PERELLÓ, J.M. (1998a).- Itinerario geològico-mineralògic per la comarca d'Anoia: des d’Odena a la Tossa de Montbui, a Carme i a la Pobla de Claramunt. Inèdit, 14 pàg. Manresa

MATA-PERELLÓ, J.M. (1998).- Recerca Geològica i Mineralògica per les comarques del Baix Llobregat i d'Anoia: des de Martorell a Masquefa i a Piera. Inèdit, 12 pàgines. Manresa

MATA-PERELLÓ, J.M. (1999).- Itinerari geològic i mineralògic per la comarca d'Anoia: des del Bruc a Piera, i des de Capellades a la Llacuna. Inèdit. 19 pàgines. Manresa

MATA-PERELLÓ, J.M. (2001).- Recorregut de recerca geològica i mineralògica per les comarques del Baix Llobregat i del Vallès Occidental: des de Terrassa i Castellbisbal a Sant Cugat del Vallès i al Papiol, i des de Martorell a Olesa de Montserrat i a Esparreguera. Algeps, sèrie $\mathrm{B}, \mathrm{n}^{\mathrm{o}} 159,14$ pag. Manresa

MATA-PERELLÓ, J.M. (2004).- El Parc Geològic de la Catalunya Central. VI Congreso Internacional sobre Patrimonio Geológico y Minero. Cercs. En premsa. Madrid

MATA-PERELLÓ, J.M. (2005).- Recorregut de recerca geològica i mineralògica per la comarca d'Anoia: des d'Òdena a la Pobla de Claramunt i al Bedorc. Inèdit. 10 pag. Manresa

MATA-PERELLÓ, J.M. (2006).- ).- Recorregut de recerca geològica, geoambiental i mineralògica per les comarques del Baix Llobregat i d'Anoia: des d'Esparreguera a Piera i a la Pobla de Claramunt. Inèdit. 14 pàgines. Manresa

MATA-PERELLÓ, J.M. (2007).- Recorregut de recerca geològica, geoambiental i mineralògica per les comarques del Baix Llobregat i d'Anoia: des d'Esparreguera a Piera i a la Pobla de Claramunt. Inèdit. 14 pàgines. Manresa 
MATA-PERELLÓ, J.M. i FONT SOLDEVILA,J. (1995).- El "Ecomuseu del riu Anoia", un instrumento didáctico para la enseñanza de la geologia. $1^{a}$ Reunión de la Comisión de Património Geológico de la Soc. Geol. España. Geogaceta, no 20, 10 pag. Madrid

RIBA,O. (1967).- Resultados de un estudio sobre el terciário continental de la parte Este de la Depresión Central Catalana. Acta Geológica Hispánica, t.. 2, Vol.1, pp. 3-8. Barcelona

RIBA, O. et altri (1976).- Geografia Física dels Països Catalans, Edit. Ketres, 254 pàgines. Barcelona

SOLÉ SABARÍS, L. (1964).- Geologia de los alrededores de Barcelona. Colección la "Nueva Geografia", Minist. de Educ. Nacional. 135 pag. Barcelona 